\title{
Wave energy and supply chain opportunities
}

\author{
A. Álvarez ${ }^{1}$, C. Anido ${ }^{2}$, S. Martín ${ }^{1}$, P.B. González ${ }^{1}$ \\ ${ }^{1}$ UDC Shipbuilding Department \\ UDC Marine Innovation Group \\ E.U.P., Universidad de A Coruña (UDC) \\ Campus of Serantes - Ferrol, 15405 A Coruña (Spain) \\ Phone: +34 981337400 Fax number: +34 981337401 \\ E-mail: aalvarez@udc.es; $\underline{\text { smartinc@udc.es; primitif@cdf.udc.es }}$ \\ ${ }^{2}$ UDC Marine Innovation Group \\ E.U.P., Universidad de A Coruña (UDC) \\ Campus of Serantes - Ferrol, 15405 A Coruña (Spain) \\ Phone: +34 981337400 Fax number: +34 981337401 \\ E-mail: cristina.anido@udc.es
}

\begin{abstract}
The evolution of research and development for the energy use of waves is deeply related to the energy crisis. Currently these technologies, which come from abundant and domestic natural resources, are gaining in importance due to the evident global warming effects and the urgent need to find sustainable solutions.
\end{abstract}

On another hand, objectives relating to installed capacity have already been presented for this incipient industry, not only by private organizations, but also by public authorities. Consequently ocean energy systems will have to be fabricated, transported, installed, operated and maintained. Therefore, at the present stage, it is fundamental to visualize and map the supply chain opportunities, while achieving a general view of all actions required to bring into operation an installation to harness wave energy.

By analysing previous reports, the present paper aims at offering an overview of the different systems developed for wave energy use and analysing the supply chain opportunities for such technologies in experimental phase.

\section{Key words}

Renewable marine energies, waves, wave energy converter (WEC), supply chain.

\section{Introduction}

In the globalized world, characterised by regional societies, economies and cultures integration, one of the major problems is the increasing energy demand. Nowadays, even the simple act of squeezing an orange implies the use of electricity, by means of a juicer. The trend towards achieving maximum comfort goes through huge power consumption due to process automation.

In recent years, governments are aware of the significance of protecting and preserving the environment. The energy production and the use of fossil fuels, to a great extent the origin of main problems facing society, raise environmental concerns. Then, it is important and urgent to find a solution to climate change and greenhouse gases emissions.

Considering the above-described framework, the present paper aims at offering an overview of the different systems developed for wave energy use and analysing the supply chain opportunities for such technologies in experimental phase.

\section{Wave energy}

Waves are generated by the wind; their height and mass grow as the wind speed increases. When it violently blows, they reach considerable size and swiftly travel over the surface of the sea, discharging their power over the obstacles on their way.

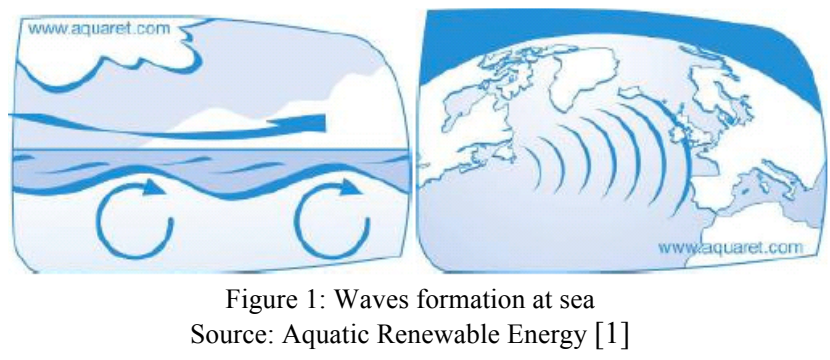

The effects of these collisions, as well as the amount of dispersed energy, are considerable and their consequences are visible at ports and breakwaters. For instance, it is worth mentioning that concrete blocks over three tonnes have been lifted and thrown away several metres off their initial location.

Throughout history [2, 3, 4] many devices have been designed to make use of wave energy. However, none of them has so far produced practical results. This is why wave energy harnessing is still, at present time, in experimental phase. 
Although the first patent for the energy use of the waves dates back to 1799, these documents increased significantly only in the seventies of the twentieth century, exceeding nowadays the number of 700 [5]. The first intensive study phase began in 1973 due to the oil crisis, which revealed the energy vulnerability of the non producing countries and the need to identify new power resources. From 1985, when the problem seemed to be solved, the research funds were brought down. A second development phase initiates in 1995, once the global warming effects became patently clear.

The wave energy conversion technologies may be classified according to different criteria $\left[\begin{array}{ll}1, & 6\end{array}\right]$. Considering the location, the devices are placed shoreline, near shore $(10-50 \mathrm{~m})$ or offshore $(>50 \mathrm{~m})$

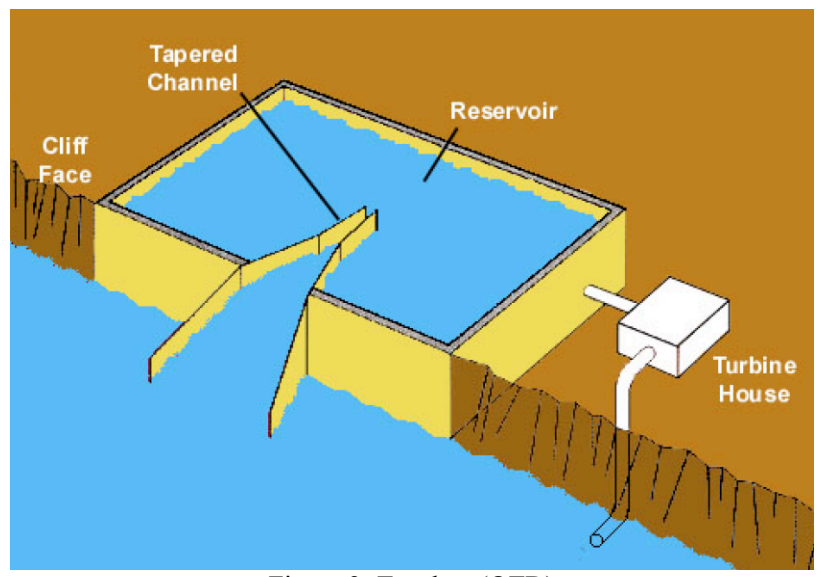

Figure 2: Tapchan (OTD)

Source: Research Institute for Sustainable Energy

The operational principle allows the following categorization:

- Articulated systems. The device rides the waves and captures the energy by selectively constraining the movements along its length.

- Bodies with wave induced motion and fixed reference. The device captures the energy by virtue of its vertical movement at or near the water surface.

- Oscillating water column (OWC). The waves cause the water column inside the structure to rise and fall, in consequence the trapped air flows back and forth past a turbine.

- Oscillating wave surge converter (OWSC). This device extracts the energy caused by the movement of water in the waves.

- Overtopping devices (OTD). The device captures the water from the waves, holds it in a reservoir and channels it through low-head turbines.

- Submerged pressure differential. The motion of the waves causes the sea level to rise and fall above the submerged device, inducing a pressure differential, which causes the structure to rise and fall with the waves.

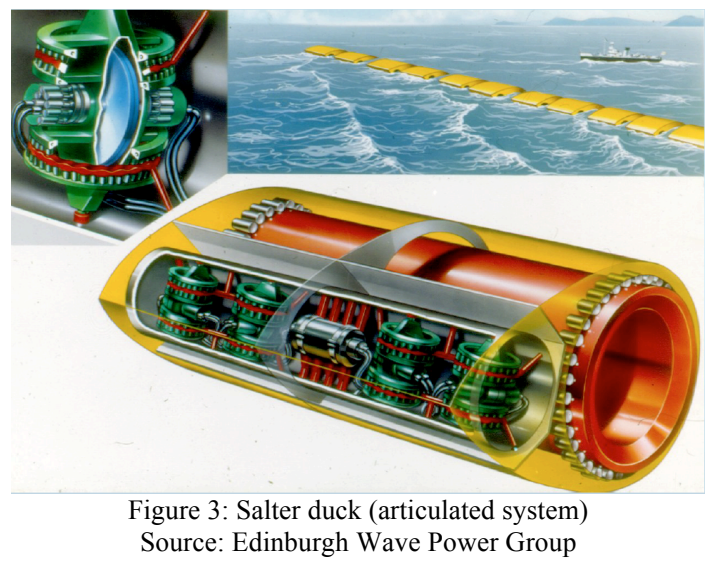

The size and the orientation of the converter consider:

- Point absorber. Small structure, usually cylindrical and, in consequence, indifferent to the wave direction, absorbing energy in all directions.

- Attenuator. Floating device working parallel to the wave direction.

- Terminator. Located perpendicularly to the wave direction, in consequence the device experiences great forces, requiring strong anchoring systems.

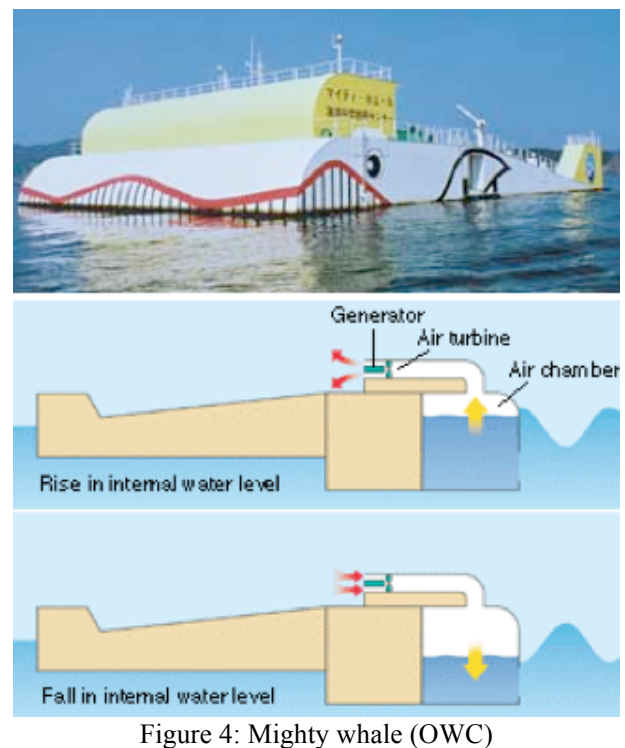

Source: Japan Agency for Marine-Earth Science and Technology

While designing a wave energy converter, different matters have to be taken into account. On the one hand, the system has to transform wave energy into usable power. On the other, the device must withstand the harsh marine conditions and work efficiently in a wide range of waves frequency and amplitude.

\section{Supply chain}

The term 'supply chain' was introduced in the early 1980s by Oliver and Webber [7]. According to Harland [8] the concept was mainly used to analyse the benefits of integrating functions in different activities, as well as the development of products and resources. 
The development of projects for renewable marine energy use would mean an important economic diversification of coastal areas [9], creating not only direct employment in the business network and manufacturing industry of devices and components, installation and operations \& maintenance, but also indirect employment.

As mentioned in the European Ocean Energy Roadmap [10], achieving $3,6 \mathrm{GW}$ of installed capacity by 2020 and approximately $188 \mathrm{GW}$ by 2050 represents a high potential and, at the same time, significant challenge. Ocean energy systems will have to be fabricated, transported, installed, operated and maintained. The industrial sector, utilities and financial markets are starting to plan for this potential and to address these challenges.

Therefore, by evaluating performance within different boundaries, it is fundamental to visualize and map [11] the supply chain opportunities, while achieving a general view of all actions required to bring into operation an installation to harness wave energy. For this purpose, the following guidelines will be followed:

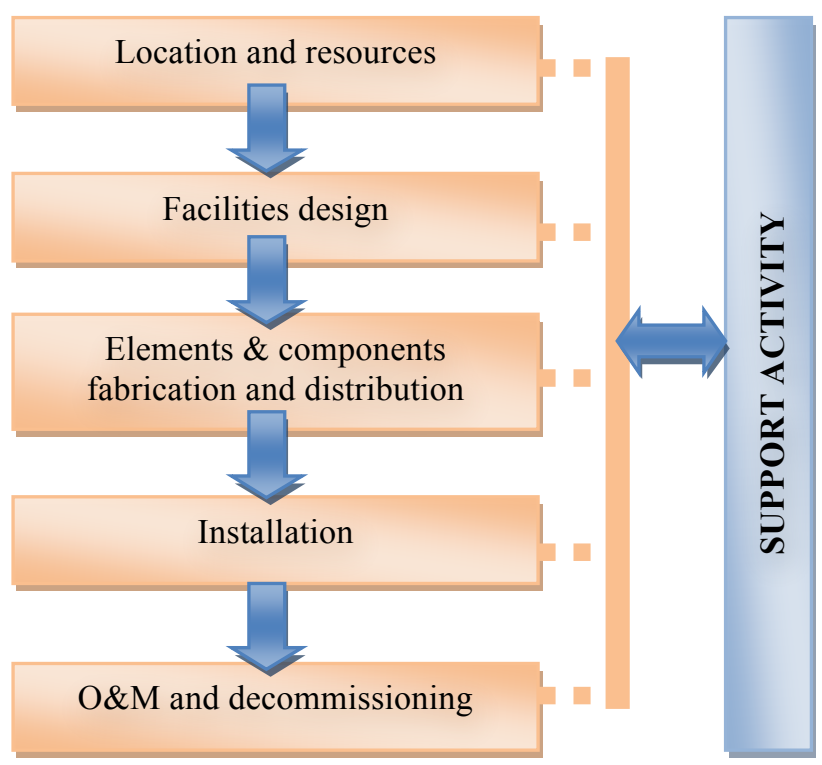

Figure 5: Supply chain model

\section{A. Location and resources}

An important asset of Spain is its coastline. So, a major problem to be faced to allow the development of ocean energy farms is their location due to social rejection, as they might affect tourism, which represents a huge source of income, and marine life. Among other, especially in initial stages, fishing and shell fishing industries might be reluctant to accept their implementation. In this case, it is fundamental to gather information on the coastline and updated data concerning depths, streams and marine subsoil composition.

The environmental impact assessments to be carried out in the marine area $[12,13,14]$ could profit from the corresponding reports developed for onshore renewable energy production systems, as well as from the knowhow gained in the onshore and offshore naval sector.

At the present moment a selection process is essential in order to foster the most suitable technologies. Bearing in mind that the ocean energy converters would initially be built inland and lately be located in the sea, specific areas would be required to unload the devices and their equipment. On another hand, considering their size and weight, port facilities might need adaptations and auxiliary machinery would be involved in their movement, location and subsequent maintenance and repair (for instance, cranes, tug ships, pontoon, floating crane, large floating platform, system mooring, buoyancy, lighting, etc.

\section{B. Facilities design}

The conventional four steps for the present process, as shown in Figure 6, are listed below:

- To define what the devices have to do.

- To design and operate the devices to comply with the objectives previously defined.

- To find evidence-based information that the devices will work as it is expected.

- To identify and remove threats.

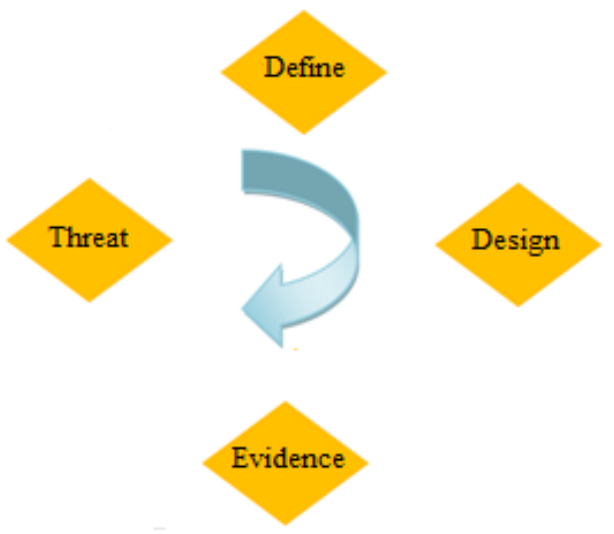

Figure 6: Four-step process

To allow the reliable identification of evidences, the following proposals might be implemented:

\begin{tabular}{|l|l|}
\hline \multicolumn{2}{|l|}{ Real situation } \\
\hline $\begin{array}{l}\text { Evidences } \\
\text { Validated simulations }\end{array}$ \\
\cline { 1 - 1 } Quantitative analysis & \\
\hline Qualitative analysis & \\
\hline Expert's opinion (written) & \\
\hline Expert's opinion (verbal) & \\
\hline No evidence & \\
\hline
\end{tabular}

Figure 7: Identification of evidences process 


\section{Elements \& components fabrication and distribution}

In order to reduce costs and terms, the information concerning potential suppliers and producers might be outlined according to the schema below:

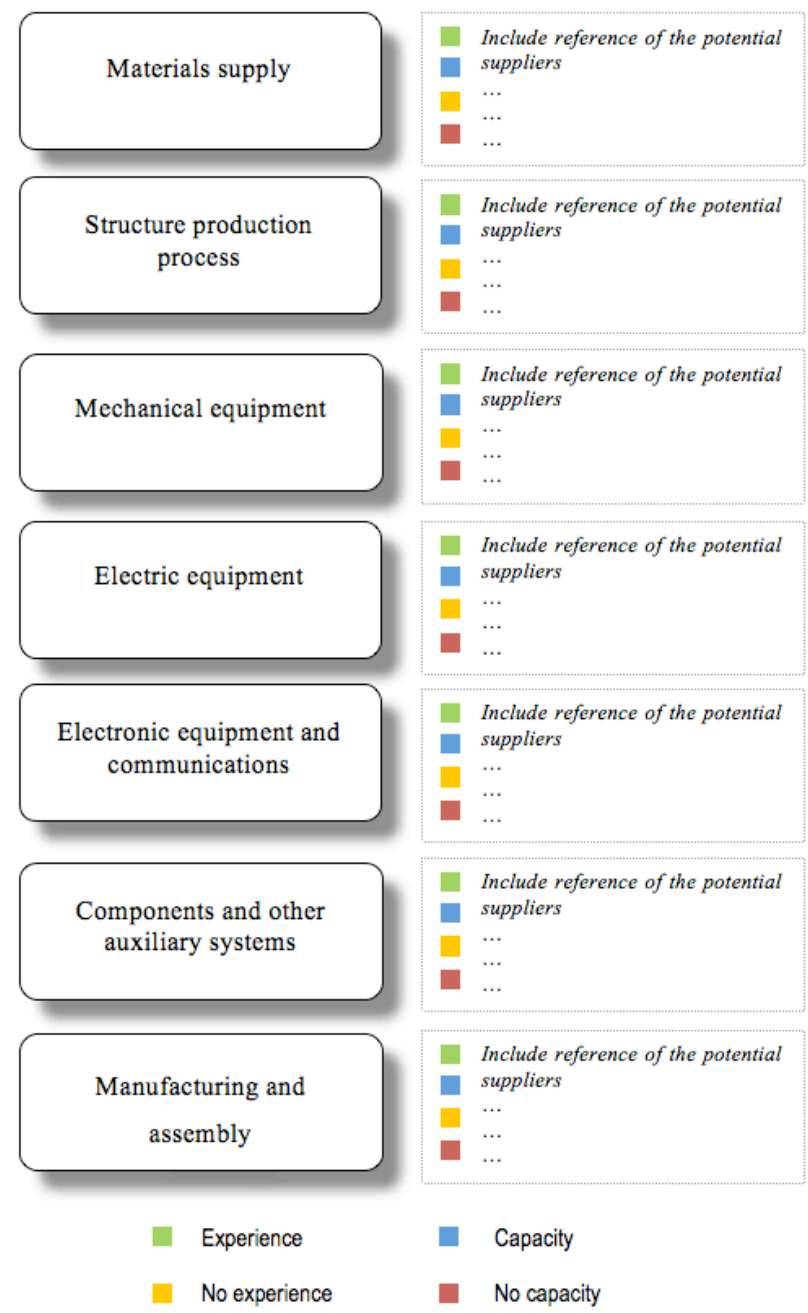

Figure 8: Schema to compile information on potential suppliers

\section{Installation}

As previously mentioned, wave energy converters may be installed at the shoreline, near shore or offshore. Each location involves advantages and drawbacks, as shown in Table I.

Table I: Advantages and drawbacks of near shore and offshore wave energy farms

\begin{tabular}{|c|c|c|}
\hline & ADVANTAGES & DRAWBACKS \\
\hline $\begin{array}{l}\text { Near } \\
\text { shore }\end{array}$ & $\begin{array}{l}\text { Moored to the bottom } \\
\text { of the sea } \\
\text { Lower costs of } \\
\text { transport, operation } \\
\text { and maintenance } \\
\text { Lower cost of energy } \\
\text { transfer to land }\end{array}$ & $\begin{array}{l}\text { Acoustic and visual } \\
\text { impact } \\
\text { Impact on marine } \\
\text { environment } \\
\text { Hazard for vessels }\end{array}$ \\
\hline
\end{tabular}

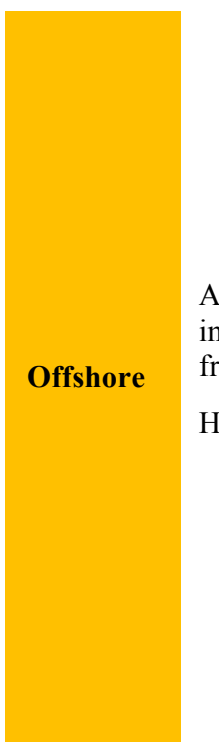

Research and development for floating systems due to greater depth

Impact on marine environment

Acoustic and visual impact not noticeable Impact due anchoring system from land

Hazard for vessels

Higher performance

Higher costs of transport, operation and maintenance

Higher cost of energy transfer to land

Need of adapted auxiliary vessels

\section{E. Operation \& maintenance and decommissioning}

The operation and maintenance policy should be based on three premises:

- Monitoring. The use of a SCADA (Supervisory Control And Data Acquisition) software would allow the control of the important magnitudes of critical systems. Communications would be carried out by fibre, integrated in the cables that transfer the energy to land.

- Predictive maintenance. Critical equipments, components and systems should be replaced at one particular moment (after a certain period of production or when their technical conditions are unsatisfactory according to an establish standard). This approach is profitable as it reduces the risk of stopping production by keeping the device in working order.

- Corrective maintenance. The procedure breakagerepair would be applied to the remaining equipments, components, systems and structures. Monitoring and periodic inspections would allow the early detection of breakdowns.

In order to carry out abovementioned actions, it would be advisable to schedule two inspections, for instance, following weather windows, one in April (at the beginning of the fair weather) and one in September (before storm period to prepare the facilities for the winter).

Concerning decommissioning, recycling and waste disposal, an action protocol should be implemented to avoid any damage, accident, spilling, etc, bearing in mind that the sea is no dumping site.

\section{F. Support activity}

So-called activities would be developed all along the process, simultaneously to stages $A, B, C, D$ and $E$. It is about, among other, tests, certification, R\&D, legal and financial consultancy, training, marketing. 
Certification provides worldwide recognition for safety and quality, due to the fulfilment of a set of rules and requirements, established before the design and construction of the facilities, being in force for their whole life cycle. This process is backed up by specific documents issued by experts.

\section{Conclusions}

In this incipient industry, it is difficult to determine what comes first: the execution of the project or the development of the supply chain? As described previously, it would be advisable to firstly outline the supply chain and map all actions required to bring into operation a wave energy farm. This would also allow to rule out inadequate technologies, relevant process at the present stage to avoid unnecessary investments.

The move towards renewable energy production chains requires effective modelling to generate and evaluate all possible energy production chain scenarios based on available resources and requirements.

The supply chain proposed in the present paper is a useful tool not only for the industrial sector, but also for governments and individuals to synthesize and evaluate possible energy production scenarios and implement them effectively.

Even when developing the supply chain, some gaps remain, relative to maintenance costs, systems reliability and energy transport. However, it is worth reminding that an important and valuable asset is the available knowhow in design, construction, commissioning, operation and maintenance of offshore oil platforms.

\section{Acknowledgement}

Norvento Energías Renovables.

\section{References}

[1] Aqua-RET. Aquatic Renewable Energy Technologies, www.aquaret.com

[2] M. Folley. "Estado del arte de las tecnologías de aprovechamiento de energía del oleaje". Conferencia COIN 2008, Ferrol, Spain.

[3] A. Clément, et al. "Wave energy in Europe: current status and perspectives". Renewable and Sustainable Energy Reviews 2002, Vol. 6, pp. 405-431.

[4] J. Falnes. "A review of wave-energy extraction". Marine Structures 2007, Vol. 20, pp. 185-201.

[5] L.R. Núñez. "Las energías renovables marinas", Boletín de Inteligencia Tecnológica 2009, nº 4, pp. 7-12.

[6] F. Miguélez, et al. La energía que viene del mar. Netbiblo, La Coruña (2009), pp. 65-92.

[7] R. Oliver, M. Webber. "Supply chain management: logistics catches up with strategy". In: M. Christopher (Ed.), 1982. Logistics: The Strategic Issues. London, pp. 63-75.

[8] C. Harland. "Supply Chain Management: relationships, chains and networks". British Journal of Management 1996, Vol. 7, pp. 63-80.
[9] P.B. González, et al. "Renewable Marine Energies in Galicia: Potential and Monitoring Tools". International Conference on Renewable Energies and Power Quality 2010, Granada, Spain.

[10] Oceans of energy - European Ocean Energy Roadmap 2010-2050. European Ocean Energy Association, Belgium, 2010.

[11] H.A. Gabbar. "Engineering design of green hybrid energy production and supply chains". Environmental Modelling \& Software 2009, Vol. 24, pp. 423-435.

[12] A.H. Fayram, A. Risi. "The potential compatibility of offshore wind power and fisheries: An example using bluefin tuna in the Adriatic Sea". Ocean \& Coastal Management 2007, Vol. 50, pp. 597-605.

[13] A.B. Gill, et al. EMF-sensitive fish response to EM emissions from subsea electricity cables of the type used by the offshore renewable energy industry. COWRIE Ltd., United Kingdom, 2009.

[14] D. Wilhelmsson, et al. Greening Blue Energy: Identifying and managing the biodiversity risks and opportunities of offshore renewable energy. International Union for Conservation of Nature (IUCN), Switzerland, 2010. 